\title{
INTERSECCIONALIDADE E MOBILIDADE TRANSNACIONAL ENTRE BRASIL E ESPANHA NAS REDES DE PROSTITUIÇÃO
}

\author{
intersectionality and transnational mobility between brazil and spain in prostitution networks
}

\author{
Joseli Maria Silva \\ Marcio Jose Ornat ${ }^{2}$
}

$a_{a} a a_{a}$

\begin{abstract}
Resumo
O objetivo desse trabalho é compreender o movimento da interseccionalidade entre raça, classe, gênero e sexualidade acionado por travestis brasileiras no processo de sua mobilidade transnacional para a Espanha. Para atingir o objetivo proposto, foram realizadas entrevistas, por meio de um roteiro semiestruturado, entre abril e setembro de 2008, com dez brasileiras atuantes como prestadoras de serviços sexuais na Espanha. As entrevistas foram sistematizadas por meio de análise de conteúdo, permitindo a elaboração de um mapa de significados em torno das experiências espaciais vivenciadas pelas travestis brasileiras na Espanha e os jogos elaborados por meio dos movimentos interseccionais. Os resultados da pesquisa permitem afirmar que o grupo de travestis investigado manejam múltiplas facetas identitárias que são acionadas em suas vivências transnacionais, de modo a constituir espacialidades paradoxais que tensionam os elementos hegemônicos da sexualidade.
\end{abstract}

Palavras-chave: Interseccionalidade, Travesti brasileira, Espaço paradoxal, Migração transnacional.

\begin{abstract}
This paper aims to understand the intersectionality movement between race, class, gender and sexuality triggered by Brazilian transvestites in the process of transnational mobility for Spain. To attain that goal, were conducted interviews, with semi-structured guidelines, between April and September 2008, with ten Brazilian trangenders which acted in providing sexual services in Spain. The interviews were systematized through content analysis, allowing the preparation of a map of meanings about the spatial experiences lived by Brazilian transgenders in Spain and the games developed through intersectional movement. The survey results allows to claim that the group of transvestites investigated manages multiple facets of identity which are brought forward in their transnational experiences and constitutes paradoxical spatialities that tensions the hegemonic elements of sexuality.
\end{abstract}

Key words: Intersectionality, Brazilian transgender, Paradoxical space, Transnational migration.

\begin{abstract}
Resumen
El objetivo de este trabajo es comprender el movimiento de la interseccionalidad entre raza, clase, género y sexualidad activado por travestis brasileñas en el proceso de su movilidad transnacional hacia España. Para llevar a cabo el objetivo propuesto, fueron realizadas entrevistas, por medio de una ruta semi-estructurada, entre abril y septiembre del 2008, con diez brasileñas que actúan como prestadoras de servicios sexuales en España. Las entrevistas fueron sistematizadas por medio de análisis de contenido, permitiendo la elaboración de un mapa temático en torno a las experiencias espaciales vividas por las travestis brasileñas en España y los juegos elaborados por medio de los movimientos interseccionales. Los resultados de la investigación permiten afirmar que el grupo de travestis investigado manejan múltiples facetas de identidad que son activadas en sus vivencias transnacionales, construyendo de esta forma espacialidades paradoxales que tensionan los elementos hegemónicos de la sexualidad.
\end{abstract}

Palabras claves: Interseccionalidad, Travestis brasileñas, Espacio paradoxal, Migración transnacional.

(1) Pesquisadora do CNPq, Prof ${ }^{a}$ Dr$^{a}$ do Programa de Pós-Graduação em Geografia da Universidade Estadual de Ponta Grossa - Av. General Carlos Cavalcanti, 4748 - CEP 84030-900, Tel.: (+55 42) 9101-1378 - joseli.genero@gmail.com

(2) Prof. Dr. do Programa de Pós-Graduação em Geografia da Universidade Estadual de Ponta Grossa - Av. General Carlos Cavalcanti, 4748 - CEP 84030-900, Tel.: (+55 42) 9961-0351 - geogenero@gmail.com

\section{aaAaa}

Revista da ANPEGE, v. 8, n. 10, p. 51-66, ago./dez. 2012.

ISSN 1679-768 X @ 2003, Associação Nacional de Pesquisa e Pós-Graduação em Geografia. Todos os direitos reservados. 


\section{INTRODUÇÃO}

O objetivo deste texto é compreender o movimento da interseccionalidade entre raça, classe, gênero e sexualidade acionado por travestis brasileiras no processo de sua mobilidade transnacional para a Espanha.

Desde o ano de 2005 o Grupo de Estudos Territoriais, do qual fazemos parte, vem desenvolvendo atividades na Organização Não Governamental Renascer (Ponta Grossa-PR), cujas ações contemplam, além de outros grupos, as travestis, utilizado na forma feminina para respeitar a auto identificação de gênero do grupo social pesquisado. Durante nosso envolvimento com travestis na cidade de Ponta Grossa, ouvíamos suas dificuldades e dores, mas também planos e anseios. Entre alguns dos sonhos mais acalentados entre elas, mesmo que fosse inatingível para algumas, o maior era ir para a Europa, atuar no mercado sexual. Essa ideia era narrada como algo que pudesse modificar suas vidas definitivamente. Nomes de travestis classificadas de 'europeias', bem como seus feitos, associados ao enriquecimento eram lembrados com profunda admiração e, para que não dizer, certa inveja entre elas. A expressão 'sou europeia mona' para expressar superioridade entre elas era comum. Iniciamos um projeto de investigação em 2007 que explorava a imigração ilegal de brasileiras para o comércio sexual na Europa e percebemos que a Espanha ainda era um dos destinos preferenciais nos anos que iniciavam o século XXI, conforme também evidenciado por Colares (2004).

O relato de que um de nós iria para a Espanha provocou uma série de propostas de trocas de favores. Segundo elas, nós poderíamos facilitar sua entrada na Espanha e em troca, elas poderiam nos 'sustentar' com dinheiro que conseguiriam fazendo programas sexuais. Explicamos que teríamos recursos do governo brasileiro e tornar-nos 'pesquisadores - cafetões' não fazia parte de nossos planos. Essas propostas acabaram constituindo várias brincadeiras, que revelaram a naturalidade com que vários atos ilícitos, como a entrada na Espanha para viver ilegalmente, repasse de somas de dinheiro, fruto da prostituição em troca de hospedagem e proteção, eram consideradas ações perfeitamente encaixadas nos códigos morais do grupo. Essa naturalização se constitui em uma vivência cotidiana de exclusão, preconceito e violência que sofrem por parte da família, da escola, do Estado e da sociedade brasileira como um todo, assim como visto em Silva (2009) e Ornat (2009). São pessoas que têm seus direitos cidadãos violados constantemente e, assim, não têm muito a perder aventurando-se em outro país, mesmo em situação de ilegalidade.

A escolha do destino do deslocamento envolve uma conjuntura que é avaliada pelas pessoas migrantes, que julgam as perdas e ganhos entre os países de origem e destino. O Brasil, nos anos 80 e 90, esteve com a economia estagnada, salários corroídos por elevados índices inflacionários e altas taxas de desemprego. Segundo os Indicadores Econômicos Consolidados do Banco Central do Brasil, a taxa média de crescimento nas décadas de 80 e 90 foi de $-0,56 \%$ e $0,95 \%$ respectivamente (http://www.bcb.gov.br/?INDECO). A Espanha, por sua vez, após o ingresso na Comunidade Econômica Europeia em 1986, passou por grandes investimentos externos e obteve forte expansão do seu produto interno bruto (PIB), ampliando oportunidades de ganhos econômicos até por volta de 2006, quando a crise econômica torna-se presente naquele país. O PIB da Espanha com índice médio de 3\% entre os anos de 1986 e 2008 (exceto nos anos de 2002 e 2003) dobrou em apenas oito anos (2001-2008), passando de U\$ 677 bilhões para um total de U\$ 1,3 trilhão.(http://www. indexmundi.com/pt/espanha/produto_interno_bruto_\%28pib\%29_taxa_de_crescimento_real. $\mathrm{html}$ ). A diferenciação espacial entre ambos os países promoveu uma atração de pessoas oriundas do Brasil para a Espanha.

O Instituto Nacional de Estadística (INE - http://www.ine.es/) da Espanha em 2006 afirma que, neste ano, havia 1.214.100 pessoas de origem latino-americana vivendo na Espanha, o que representa $31,26 \%$ do total do conjunto de imigrantes que vivem naquele país. Segundo Vicente (2006) houve um aumento de $250 \%$ de imigrantes latino-americanos, apenas entre os anos de 2001 
e 2005. O Brasil, conforme os dados de Araujo (2008), é o sexto país mais importante em termos de origem de população vivendo na Espanha, mas é o primeiro em termos de taxa de irregularidade de situação, chegando a 61\%. Segundo a autora: "és de destacar la persistencia de uma gran proporción de irregularidad em el caso de brasileños" (ARAUJO, 2008, p. 204). As altas taxas de irregularidade no processo migratório torna o grupo de brasileiros mais vulnerável aos processos de exploração de várias naturezas.

Embora boa parte da compreensão dos processos migratórios entre países fundamente-se nas transformações do mercado laboral, este elemento não é fundamental no caso do fluxo de travestis. No Brasil, como em outros países, as oportunidades de empregabilidade são raras para elas. Assim, o elemento fundamental é avaliar a lucratividade da prostituição entre o país de origem e de recepção dessa população marginalizada.

Ao iniciar a pesquisa, foi imediatamente detectada a impossibilidade de precisar o número de travestis brasileiras que estavam em situação de prostituição na Espanha. As travestis brasileiras figuravam apenas nos sites e jornais que publicam anúncios de venda de serviços sexuais ou, ainda, em notícias policiais, quando a 'Guardia Civil' divulga alguma ação classificada como sendo de combate ao 'Tráfico de Seres Humanos'. A corporalidade móvel da existência travesti impossibilita sua visibilidade em um mundo cuja classificação dos gêneros está organizada de forma rígida e bipolar (masculino e feminino), fundamentada na forma dos órgãos genitais. Os possíveis dados e registros das travestis brasileiras em instituições da Polícia Nacional da Espanha e órgãos alfandegários, são masculinos, embora essas pessoas tenham uma identificação de gênero feminino.

A invisibilidade das travestis brasileiras nas estatísticas dos órgãos oficiais da Espanha contrasta fortemente com a visibilidade 'glamourosa' das propagandas de prestação de serviços sexuais, seja em panfletos, sites de internet (http://www.travestiguide.com/ e http://www.rincontranny.com/) ou jornais (El país e El mundo). Nesse sentido, o desenvolvimento da pesquisa exigiu estratégias qualitativas como entrevistas e observações, além da exploração de anúncios de jornais e sites em internet. As entrevistas tiveram a participação de dez travestis brasileiras, atuantes como prestadoras de serviços sexuais na Espanha. O roteiro de entrevista seguiu três eixos investigativos: 1) características do Brasil que impulsionam o desejo de ir para Europa; 2) estratégias para ultrapassar fronteiras nacionais; 3) brasileiras vivendo em atividade comercial sexual na Espanha. As entrevistas foram sistematizadas por meio de análise de conteúdo, como proposto por Bardin (1977) e, as observações realizadas entre fevereiro e setembro de 2008 foram registradas em diário de campo.

A análise de conteúdo foi realizada pela transcrição íntegra das falas das travestis que foram posteriormente organizadas a partir de categorias discursivas chamadas de 'evocações'. A intensidade das evocações e a semelhança argumentativa constitui um eixo semântico hierarquizado que se apresenta nas tendências discursivas. É através do mapa conceitual resultante da análise de conteúdo das entrevistas concedidas pelo grupo que os argumentos textuais são estabelecidos neste artigo.

A metodologia de análise escolhida implica a caracterização do grupo de pessoas que fizeram parte da pesquisa. $\mathrm{O}$ quadro 1 traz uma síntese de algumas características das participantes da investigação.

As informações sobre autoidentificação de gênero representadas no quadro, devem ser esclarecidas. Apesar das travestis brasileiras estarem vivendo em um contexto político espanhol de conquistas de direitos sociais da população LGBT (Lésbicas, Gays, Bissexuais e Transgêneros), elas rejeitam os termos 'transgénero' ou 'mujertrans', largamente utilizados pelas instituições políticas. O termo 'travesti' é considerado pejorativo e atrasado, sendo aconselhável sua substituição na sociedade espanhola. As brasileiras, no entanto, não compartilham das denominações consideradas corretas pela cultura espanhola. Com exceção de Divina, que vive na Espanha desde 1974 e realizou cirurgia de transgenitalização, as outras duas pessoas que disseram se identificar como transexuais declaram que 'ainda são travestis', mas que sonham, um dia, poder fazer a referida cirurgia. Nesse sentido, o termo 'travesti' para as brasileiras ainda remonta a ideia de ter um pênis e fazer uso dele. 
Quadro 1 - Características das participantes da investigação

\begin{tabular}{|c|c|c|c|c|}
\hline $\begin{array}{l}\text { Nome } \\
\text { Fictício }\end{array}$ & Idade & $\begin{array}{c}\text { Auto } \\
\text { identificação }\end{array}$ & $\begin{array}{l}\text { Procedência do } \\
\text { Brasil }\end{array}$ & Local de prostituição \\
\hline Ágape & 26 & Travesti & Maranhão & Rua $^{1}$ \\
\hline Andrômeda & 33 & Travesti & Interior do Ceará & Rua \\
\hline Talia & 26 & Travesti & Novo Hamburgo & Rua \\
\hline Moiras & 20 & Travesti & Rio de Janeiro & Rua \\
\hline Iris & 20 & $\begin{array}{l}\text { Transexual/ } \\
\text { Travesti }\end{array}$ & Interior da Paraíba & Piso $^{2}$ \\
\hline Pandora & 38 & Travesti & Porto Alegre & Piso \\
\hline Tétis & 31 & Travesti & São Paulo & Piso \\
\hline Eudora & 28 & Travesti & Natal & Piso \\
\hline Eurídice & 25 & $\begin{array}{l}\text { Transexual/ } \\
\text { Travesti }\end{array}$ & João Pessoa & Piso \\
\hline Divina & $\begin{array}{c}\text { Não } \\
\text { declarou }\end{array}$ & Transexual & Bagé & $\begin{array}{l}\text { Piso (atua como a encarregada/ não faz programas } \\
\text { sexuais) }\end{array}$ \\
\hline
\end{tabular}

(1) Ruas paralelas à Gran Via como Calle del Desengaño, La Puebla, Valverde e Fuencarral e Paseo de la Castellana;

(2) Piso é a denominação de apartamentos privados em que são desenvolvidas as atividades de prestação de serviços sexuais.

Desta forma, o presente texto, cujo objetivo é compreender o movimento da interseccionalidade entre raça, classe, gênero e sexualidade acionado por travestis brasileiras no processo de sua mobilidade transnacional para a Espanha, está estruturado em quatro seções. A primeira discute a necessidade de ultrapassar a imaginação geográfica do espaço, a fim de construir a visibilidade científica do grupo de travestis. Na segunda seção foram exploradas, por meio de seus depoimentos os elementos estruturadores das redes transnacionais da prostituição travesti. As duas seções seguintes abordam as espacialidades por elas constituídas e sua versão sobre o tráfico internacional de pessoas.

\section{INTERSECCIONALIDADE E ESPAÇO PARADOXAL: CONCEITOS FUNDANTES NA COMPREENSÃO DO ESPAÇO VIVENCIADO POR TRAVESTIS BRASILEIRAS NA MOBILIDADE TRANSNACIONAL PARA ESPANHA}

A compreensão da relação entre espaço e existência travesti torna-se impossível a partir de critérios como objetividade e materialidade, pois a fluidez de sua corporalidade, a invisibilidade de sua existência formal, a amplitude e a intensidade de sua mobilidade locacional desafia o espaço material e facilmente cartografável. Contudo, as travestis brasileiras, apesar de suas vidas abjetas, constituem conexões espaciais altamente complexas, dinâmicas e perfeitamente compatíveis com o mundo contemporâneo globalizado. Inapropriadas, desalojadas, ilegais e invisíveis, as travestis constituem espaços imbricados ao processo de globalização e, ao contrário do que muitos imaginam, elas não são anomalias sociais ou desvios do sistema de capital por realizarem um trabalho informal e moralmente condenável pela sociedade burguesa. Elas são elementos contraditórios e complementares da sociedade global.

Portanto, para construir a visibilidade espacial de travestis brasileiras em seu movimento transnacional é preciso, tal qual argumentam as geógrafas Massey (2008), McDowell (1999), Rose (1993 e 1999) e Valentine (2007), pensar o espaço enquanto relacional, definido nas práticas socioespaciais, nas relações sociais e de poder.

Um espaço relacional implica reconhecer as relações entre pessoas marcadas por diferenciações sociais que constituem suas identidades permanentemente confrontadas socialmente, cuja espacialidade é um dos elementos dessa construção. O gênero, a classe, a raça, a sexualidade, a idade, a 
religião e assim por diante são elementos de diferenciação entre pessoas e grupos, marcando sua existência. Embora cada um desses marcadores sociais tenha sido fragmentado nas análises científicas, há argumentos de que o ser humano vivencia simultaneamente vários desses elementos e, portanto, eles devem ser compreendidos de forma 'interseccionada'.

Rose (1993) tem argumentado a necessidade de se pensar o gênero enquanto uma categoria identitária interceptada por diversas outras, como classe, raça, sexualidade, etc., evidenciando a pluralidade da vivência humana. Cada pessoa experimenta sua existência, localizada socialmente por várias categorias que se interceptam e essa singularidade é mediada espacialmente. Assim, por exemplo, a interseção (gênero / raça) de uma mulher negra no Brasil, possibilita determinadas experiências muito distintas daquelas que podem ser vividas em um país europeu ou africano. A articulação complexa de categorias sociais é chamada de interseccionalidade e tal conceito, já utilizado em várias outras ciências humanas, foi defendido como importante elemento de análise geográfica por Valentine (2007). Apesar das pessoas se constituírem por diversos elementos de diferenciação, há um movimento entre eles, dependendo da relação socioespacial estabelecida com outros grupos ou seres humanos. Assim, alguns elementos podem ser acionados com maior intensidade de visibilidade para obter vantagens, enquanto outros podem ser camuflados.

O movimento de interseccionalidade explora a forma como os elementos identitários vão sendo acionados nas diferentes relações, marcadas por tempo e espaço. As travestis brasileiras, que exercem atividades de prostituição na Espanha, acionam categorias sociais em um complexo jogo de poder com outros grupos sociais que envolvem a raça, a classe, o gênero e a sexualidade. O espaço assim conformado pelas relações interseccionais é dinâmico e a posição dos sujeitos confrontados é paradoxal, superando a ideia que opõe sujeitos dominados e dominantes em posições fixas. Pensar a vivência das travestis brasileiras que superam as barreiras transnacionais em uma sociedade globalizada implica conceber uma imaginação espacial complexa, tal qual Rose (1993) nos oferece em sua teoria do espaço paradoxal.

O espaço enquanto uma entidade essencializada ou pré-discursiva não existe. O que se convencionou chamar de espaço na Geografia nada mais é do que criações humanas para compreensão de nossa realidade dentro de um campo específico de conhecimento. A palavra espaço, que acabou se tornando um dos conceitos fundamentais da Geografia, possui inúmeras interpretações defendidas por diversos geógrafos em diferentes tempos, países e afiliados em várias correntes filosóficas. Entre a pluralidade de possibilidades interpretativas, a vivência travesti é possível de ser compreendida por uma imaginação geográfica que desafia as ideias hegemônicas e torna visível a resistência daqueles cujas identidades são negadas.

Massey e Sarre (1999) argumentam que as identidades são permanentemente instituídas por meio da construção/desconstrução de espaços. O espaço está em permanente processo de produção e isso traz um importante caráter de abertura para uma imaginação geográfica que possa conceber o espaço enquanto praticado e relacional. Nessa linha de raciocínio, Rose (1999) constrói a possibilidade de pensar o espaço como articulação de discursos, fantasias e corporeidades, o que o torna complexo, contraditório e instável. Para Rose (1999) o espaço relacional não se institui por meio da relação de pessoas preexistentes ou essencializadas mas nas interações performáticas. Rose (1999) toma por base o conceito de performatividade de Judith Butler quem considera o gênero como um fazer eterno, enquanto prática repetitiva, sendo assim performático. É a prática que constitui as identidades de gênero e sendo assim, tais práticas constroem a ideia do que o gênero supostamente é. Portanto, o gênero não existe em si, mas é uma representação que ganha concretude nas práticas cotidianas construindo a falsa noção de estabilidade. Assim, Rose (1999) argumenta que o espaço é também um fazer, não é preexistente ao fazer, sendo tal processo fruto da articulação de performances relacionais.

O gênero performático de Butler (1990) sugere que não há gênero essencializado, mas que ele se faz em atos repetitivos dentro de uma matriz de inteligibilidade social da sociedade hetero- 
normativa, o que lhe confere um falso caráter de estabilidade e naturalidade. Entretanto a matriz apresenta fissuras e a mesma estrutura que constitui o padrão heteronormativo é a que produz, de forma simultânea, os seres abjetos. Os seres abjetos são aqueles seres que não possuem o estatuto de humanos, mas são necessários, contraditoriamente, para definir o campo constitutivo dos sujeitos. O abjeto para Butler (1993) designa as zonas invisíveis e inabitáveis da vida social, mas que estão densamente povoadas por aqueles que não usufruem do estatuto de sujeitos. Entretanto, sua existência é necessária para circunscrever o domínio do poder dos sujeitos. O espaço produzido por essa performance é particular, fruto de um tipo de relacionalidade. Portanto, outras relacionalidades podem instituir outros espaços, segundo Rose (1999). O espaço, na concepção de Rose (1999), é praticado, dinâmico, interativo e se faz de performances situacionais das relações entre si e outros. Assim o espaço é plástico e uma vez que pode ser praticado por performances do poder heteronormativo, também pode ser praticado pelos seres abjetos das zonas inabitáveis e invisíveis.

A imaginação geográfica de Rose (1999) já havia sido desenvolvida em certos aspectos em sua proposta de espaço paradoxal em Rose (1993). Para romper com a ideia do espaço praticado apenas pelas representações dominantes é necessário captar o sentido da relação entre si e outros de forma mutável e passível de transformação das direções dos eixos de poder em situações particulares. Na proposição desta geógrafa o espaço paradoxal é imaginado por meio da relacionalidade, contudo ultrapassando a ideia fixa e bipolarizada entre dominados e dominantes, trazendo a ideia de centro e margem da relação, cujas posições são mutáveis. Esse perfil de relacionalidade possibilita uma imaginação geográfica que pode trazer para visibilidade as práticas de grupos sociais de pequena expressão material de poder.

Vários grupos sociais vulneráveis ao poder masculino, branco e heterossexual têm sido estudados, conforme Rose (1993), por meio do conceito de território em uma configuração oposicional entre 'insider/outsider', ou seja, os de dentro e os de fora das fronteiras do espaço conquistado. Nessa perspectiva, o espaço conquistado pelo grupo que exerce o poder torna o 'outro' da relação um elemento não constitutivo do espaço conquistado, pois está posicionado fora dele. Rose (1993) argumenta que no espaço conquistado há também os grupos subordinados que não estão passivos, mas na margem das relações de poder e essa posição pode ser situacional, pois, embora na margem, não estão passivos, mas resistem aos poderes daqueles que conquistaram o espaço.

Sob a perspectiva de Rose (1993), no território do conquistador há também o conquistado, que não é passivo, que coloca em ação sua força de resistência e dá sentido ao poder exercido, gerando uma relação simultaneamente contraditória/complementar, já que a prática do poder só se justifica pela ação que resiste a ele. Esta perspectiva nega a visão simplista e oposicional 'insider/ outsider', e ela é potencial para se construir a visibilidade de grupos não hegemônicos, pois rompe com a visão universal do poder.

A universalidade do poder do conquistador na constituição de territórios é uma estratégia que tem como finalidade negar a existência de fragmentações e diferenciações internas com o intuito de tornar invisíveis e neutralizar as forças que possam desestabilizar a ordem e contestar o território estabelecido. O espaço paradoxal considera a multiplicidade de identidades dos seres, contemplando aspectos de plurilocalidade dos seres humanos que fazem parte da análise, assim como as múltiplas dimensões que se configuram com o acionamento das identidades tensionadas, numa relação contraditória e complementar, entre 'nós' (considerados centro da configuração) e os 'outros' (considerados margem da configuração). É necessário considerar que essas posições não são fixas, elas estão sempre tensionadas pelos dois polos da configuração espacial (centro/margem) e podem mudar de posição, de modo que constituem um processo sempre em transformação. Assim, é o movimento permanente e múltiplo que pode provocar uma desestabilização da configuração estabelecida e gerar uma nova posição.

O espaço paradoxal proposto por Rose (1993) é complexo, envolve variadas articulações e dimensões e se constitui em uma interessante construção teórica e metodológica na Geografia. Qualquer pessoa não pode ser concebida apenas como constituindo um gênero, mas também a sexualidade, 
a raça, a religião e a classe social, que são vivenciadas espacialmente e temporalmente. As diferentes facetas identitárias são construídas e reconstruídas por meio de um processo de mutualidade e reconhecimento, envolvendo os seres humanos em relação a outros seres. Certamente todos os elementos identitários enumerados são vivenciados simultaneamente pelas pessoas. Contudo, é na experiência espacial e temporal que um ou outro elemento torna-se mais expressivo e tensionado com outros grupos também complexos.

A experiência de travestis brasileiras que rompem as fronteiras nacionais e acessam outros países pode ser visível apenas por uma imaginação geográfica que ultrapasse a dicotomia, a simplista oposição entre dominados e dominantes e permita evidenciar suas práticas complexas e fluidas que tem permitido sua existência, apesar de toda forma de poder e violência à que estão submetidas.

\section{FANTASIAS, DESEJOS E RACIALIDADES COMO ELEMENTOS DAS REDES TRANSNACIONAIS DA PROSTITUIÇÃO TRAVESTI}

A mobilidade transnacional de travestis brasileiras para a Espanha se estabelece em uma mediação de elementos entre o país de origem (Brasil) e o de destino (Espanha). As evocações das travestis se concentraram em três importantes eixos discursivos: 50\% das evocações estiveram relacionadas à ideia de deixar o Brasil devido à discriminação sofrida pelo fato de ser uma travesti; $31 \%$ trouxeram elementos ligados à falta de oportunidades financeiras no Brasil. Além disso, 16\% das evocações estavam ligadas ao desejo de 'ser uma europeia', o que ajudaria a superar, tanto o preconceito como os problemas financeiros. Os 3\% restantes das evocações estavam vinculadas ao fato de estar distante da família e poder transformar o corpo sem criar conflitos. As falas transcritas a seguir constituem a síntese da análise do conteúdo emitido nas entrevistas:

Eu deixei o Brasil porque eu queria crescer e lá estava difícil. No Brasil, você trabalha, trabalha, trabalha e não cresce porque o governo não te oferece nada para você crescer. Daí, você já sendo uma travesti, transexual, homossexual ou sei lá o que queiram te chamar, porque a nossa sociedade tem essa mania hipócrita em querer te classificar, te dar rótulo, títulos. Infelizmente, no Brasil, você funciona pelo dinheiro, você vale o que você tem na carteira e você não quer passar a tua vida inteira sendo mal tratada. Se você tem a oportunidade, você sai fora mesmo. Porque no Brasil você não vai encontrar uma travesti ou transexual assumida, trabalhando como uma caixa de supermercado, numa loja. Você não vai encontrar como médica. Talvez agora já tenha porque eu estou fora do Brasil faz cinco anos (Entrevista realizada com Pandora, em Madri, em 16/09/2008).

Ir para a Europa, enriquecer e voltar ao Brasil com uma nova inserção social e familiar faz com que a representação espacial positiva concebida em torno dos países da Europa seja reforçada pelo desejo. Os comentários que circulam dentro do grupo valorizam as experiências no exterior, como ressaltado no trabalho de Patrício (2009) e, pouco se fala nas dificuldades encontradas. Todas as evocações, ou seja, 100\%, sobre as informações recebidas da Espanha por outras pessoas eram positivas, como evidencia as falas das travestis:

Eu, por exemplo, tenho 20 anos e os jovens da minha geração ou das novas gerações, se espelham, por incrível que pareça, nas pessoas mais velhas. Tanto na parte boa como na parte ruim. Então como conhecemos muitas que são cafetinas, são riquíssimas, tem muito dinheiro, poder, tem apartamento e não sei mais o que, então quando você ouve: Olha, a fulana foi pra Espanha e voltou rica. Já viu né. Às vezes nem é tão rica assim, às vezes tem uma bolsa Doce Gabana porque ganhou de um cliente, mas a gente pensa que tá podendo. Daí a gente pensa, ah! Vô também. Entendeu? É aquela mesma história da ilusão (Entrevista realizada com Moiras, em Madri, em 15/05/2008).

Segundo elas, há uma omissão dos fracassos das experiências no exterior dentro do grupo, o que mantém o imaginário positivo desses países. $\mathrm{O}$ fracasso desta empreitada para elas é sinônimo 
de incapacidade pessoal e não de elementos sociais. Assim, em geral, são omitidas no grupo, como relata o trecho modelo a seguir:

A gente sempre sabe das outras né e é por isso que quer vir. Só que a gente vê a parte boa, quando elas voltam com dinheiro, compram carro sabe. $O$ lado ruim ninguém conta e nem vai contar porque não quer parecer que não deu certo, vai parecer fracasso (Entrevista realizada com Andromeda, em Madri, em 14/05/2008).

Entretanto, a experiência concreta vivida na Espanha traz novas percepções sobre o país, 86\% das evocações estavam relacionadas com as decepções quando avaliaram aquilo que sonhavam e o que encontraram na Espanha e apenas 14\% das evocações correspondiam às expectativas inicias, como pode ser visto nos comentários que se seguem:

Olha, eu penso que tem muita ilusão com a Europa sabe. Que não tem gente passando fome, passando mal na Europa. Na verdade não é assim. Claro, a Alemanha é diferente. Não posso comparar com o Brasil, nem as pessoas, nem o formato e nada. Mas aqui na Espanha eu não vejo muita diferença do Brasil não, em termos de violência, em termos de assalto sabe. Inclusive na diferença social. Nessa rua mesmo se você vem de dia, tem gente fazendo compra, gente fina, de puma, de carrão. Se você vem de noite tem puta, tem travesti, tem bêbado. Pra mim, o nível de vida da Espanha é idêntico ao do Brasil. Em termos de violência, prostituição, tudo. Eu pensava assim como todos, que quem vive na Europa é assim milionário. É verdade. As pessoas pensam assim. Dior, Doce Gabana, principalmente viado. Cabeça de viado é assim meu bem. (...) Então quando a gente pensa que vai sair do avião e só vai ver assim o glamour, vai ver só gente passando bem, que não tem pobreza, que ninguém passa fome, que ninguém vive na rua, que as casas todas são lindas e maravilhosas, que tudo são flores. Na verdade não é (Entrevista realizada com Moiras, em Madri, em 15/05/2008).

Das dez travestis que participaram da pesquisa, apenas duas delas não eram prostitutas no Brasil antes de vir para a Europa. Talia trabalhava em um escritório e realizou o processo de transformação corporal na Espanha, quando iniciou a atividade de prostituição e Iris alega ter sido traficada. As evocações sobre os locais de atuação no Brasil que possibilitaram a vinda para a Europa em $75 \%$ das evocações evidenciou que a passagem pelas capitais brasileiras constitui um nó fundamental de ligação com o exterior. As demais evocações que relatam a vinda direta de uma pequena cidade brasileira para o exterior, estavam ligadas aos comentários das duas travestis que, quando moravam no Brasil, não exerciam a prostituição. As estratégias para passar pelas fronteiras nacionais são desenvolvidas por uma rede de pessoas articuladas entre si, constituindo redes de pessoalidade que facilitam a elas vencer os limites fronteiriços. As dificuldades de acesso colocadas pelos órgãos de imigração nos aeroportos são logo ultrapassadas, como pode ser constatado pelos trechos que seguem:

Então, hoje, a Europa está muito difícil. Uma porque a entrada está mais difícil. (...) as pobrezinhas [referência às travestis] vêm, descem na Áustria, não sei onde, daí tem um homem que espera elas lá, que espera elas na fronteira. Tem umas que vem pelas montanhas. É um sacrifício viu. Depois, imagina você chegar e te mandarem embora? Imagina você, 24 horas viajando por terra. Na Áustria tem que pegar um taxista, tem que pagar o taxista pra cruzar pra não sei onde. Teve uma menina que veio pela Itália, lá posou na casa de uma conhecida nossa em Milão e só depois entrou aqui na Espanha. Porque os países que fazem parte do mercado comum já não têm aduana e daí já é mais fácil entrar por terra. Elas agora descem em países que não estão visados pela imigração. Se vier direto para Madri, Barcelona, já no avião já comunicam o pessoal no aeroporto. A Europa está muito ruim para vir (Entrevista realizada com Divina, em Madri, em 02/06/2008).

As estratégias evidenciadas pelas travestis para driblar os mecanismos de regulação, fazem parte do paradoxo que mescla relações legais e ilegais que constitui um mesmo processo espacial. A dinâmica de migração transfronteiriça realizada pelas travestis faz parte do que Sassen (2003) considera como 'Contrageografías de la globalización' que, segundo ela "son dinámicas y cambiantes 
en sus características de emplazamiento: en algún sentido son parte de la economía sumergida, pero también es evidente que utilizan la infraestructura institucional de la economía regular" (SASSEN, 2003, p. 42).

As travestis, pessoas de baixos rendimentos e baixa escolaridade, como visto em Silva (2009) e Ornat (2009), associada a uma vida de exclusão, pobreza e preconceito devido sua orientação sexual no Brasil se constitui em elementos propulsores para a imigração e uma possibilidade de modificar sua posição econômica e de respeitabilidade social. Quaisquer elementos de dificuldade ou de risco que as travestis possam sofrer não se constituem em dificuldades intransponíveis diante das dificuldades já vivenciadas em território brasileiro e 'ser uma europeia', mesmo que seja uma experiência difícil no exterior, transforma-se, na volta ao Brasil, em um forte elemento de valorização, reposicionando a travesti nas relações de poder em seu espaço de origem, conforme relatado nas pesquisas de Pelúcio (2010) e Patrício (2009).

O mesmo corpo travesti desprezado pela sociedade brasileira, ganha novo sentido na Espanha, pois em uma sociedade que realizou várias conquistas de direitos cidadãos para os grupos LGBTs, o fato de serem travestis provoca menos preconceito do que o fato de serem brasileiras. Desta forma, 71,5\% das evocações sobre preconceito na Espanha estiveram relacionadas à nacionalidade brasileira e apenas $28,5 \%$ apontam terem sido desrespeitadas por serem travestis. No trecho de relato abaixo, Pandora compara a sociedade espanhola como mais evoluída e a brasileira como atrasada no que diz respeito à aceitação de sua orientação sexual:

Aqui fora eu não posso dizer que sofri preconceito por minha opção sexual. Apesar que eu me esforço ao máximo para parecer mulher, me esforço fazendo minhas cirurgias. Já fiz uma série de cirurgias plásticas para isso. E como eu tenho uma aparência feminina, as pessoas não notam muito. É raro alguém passar por mim e já perceber que eu sou uma travesti. Às vezes me chama até de senhora ou senhorita. Agora, no Brasil, a sociedade é muito atrasada com relação ao preconceito. Por incrível que pareça, se você for fazer um balanço no mundo, eu acho que o lugar que mais tem travesti e transexual é no Brasil. E é para mim o país mais preconceituoso até o dia de hoje. Isso não me entra na cabeça. Não me entra. É falta de cultura, de educação e de investimento do governo. Agora, como brasileira, às vezes quando notam sua fala, depende da região que você vai tem mais preconceito sim (Entrevista realizada com Pandora, em Madri, em 16/09/2008).

A nacionalidade brasileira desvantajosa do ponto de vista do preconceito é simultaneamente vantajosa na perspectiva do desejo no mercado sexual espanhol. As travestis brasileiras são consideradas as preferidas dos clientes e descritas com adjetivos vantajosos em relação às travestis de outras nacionalidades. As categorias discursivas utilizadas nas falas sobre sua relação com os clientes evidencia uma imagem de desejo e satisfação associada à sua nacionalidade. Neste caminho, 47,5\% das evocações referem-se às brasileiras como sensuais, 19,5\% como bonitas/lindas, $14 \%$ como alegres/divertidas, $10,5 \%$ como amáveis/doces, $7,0 \%$ como sendo 'bem dotadas' e $1,5 \%$ mentirosas. Divina, administradora de um piso de luxo de travestis em Madrid explica:

(...) as brasileiras não as mais requisitadas. Elas são as mais pedidas, porque elas são as mais bonitas, femininas e ao mesmo tempo mais bem dotadas, sabe 'polla gorda' (pênis grande ). São mais 'guapas' (bonitas). As brasileiras são muito diferentes das espanholas. As brasileiras são muito femininas. Qualquer brasileira é mais feminina que uma espanhola. As brasileiras há muito tomam hormônio e se produzem. As espanholas, nossa, até pouco tempo se desse um beijo, você sentia a barba. A brasileira não, ela já vem linda, hormonada, siliconada. As mais pedidas são as brasileiras. (...) As brasileiras são mesmo as preferidas. Não tem para as outras. A brasileira é muito bonita, tem bundão, peitão, são muito doces ao falar. Das portuguesas eles não gostaram muito não. Não deu certo. Gostam de brasileiras. De brasileiras mesmo. As portuguesas aqui, nossa era até estranho perto das brasileiras porque a forma de falar, de se comportar, as brasileiras são muito mais sedutoras mesmo (Entrevista realizada com Divina, em Madri, em 02/06/2008). 
A nacionalidade brasileira vincula-se à corporalidade como visto no trecho de depoimento acima, bem como ao gestual e a forma como outras nacionalidades são consideradas menos atrativas. Corrêa (1996) argumenta que a construção da mulher brasileira está profundamente marcada por elementos presentes no discurso dos colonizadores e relatos de viajantes que evocam a tropicalidade, a amabilidade, a naturalidade com a nudez e a disponibilidade sexual dos indígenas, como pode ser visto no depoimento de Pandora:

(...) a brasileira não, ela tem aquela identidade tropical, alegria, diversão. São mais carinhosas, alegres, divertidas, extrovertidas, simpáticas, doces e mais sensuais. As brasileiras são muito mais sensuais e isso tudo conta. Em geral eles associam a gente ao clima tropical, quente, e automaticamente, a uma mulher quente, uma mulher ardente, uma mulher apaixonada. Como eu posso te explicar, é uma mulher que se entrega completamente ao prazer. É mais quente na cama, mais carinhosa, é mais tudo. Aqui a mulher europeia faz sexo, como manutenção do casamento, uma vez por mês, como se fosse uma espécie de revisão de carro sabe. Como se fosse uma obrigação, porque na verdade elas não casam com um marido, casam com um cartão de crédito (Entrevista realizada com Pandora, em Madri, em 16/09/2008).

Tanto a nação como a raça são aqui compreendidas como socialmente construídas. A ideia de nacionalidade brasileira foi forjada na sua relação contraditória/complementar entre modernidade/ colonialidade. Schwarcz (1994), argumenta que a imagem de Brasil foi produzida pelas impressões deixadas pelos diversos viajantes e naturalistas que tiveram suas ideias acolhidas por intelectuais brasileiros como sendo uma nação mestiça, híbrida e, portanto degenerada do ponto de vista humano, mas com uma natureza exótica, poderosa, bela e generosa. Assim, conforme Costa (2008), os conceitos de raça e meio estiveram profundamente vinculados à ideia de nação brasileira que até hoje persiste no significado da brasileira na Espanha. Os significados em torno da nacionalidade/ racialidade brasileira são utilizados pelas travestis que mobilizam elementos de brasilidade para tirar vantagens no mercado sexual. Sua imagem de feminilidade, próxima da natureza significada como generosa, bela, exuberante e exótica e, ao mesmo tempo, degenerada moralmente, profundamente sexualizada pela natureza selvagem de uma sociedade composta da mistura de raças.

Os elementos simbólicos da nação são amplamente utilizados pelas travestis brasileiras, bem como os elementos da natureza. A travesti (figura 1), cujo nome é anunciado como 'Anaconda Brasil' exacerba a nacionalidade brasileira vestindo-se com estampas da bandeira brasileira e seu nome é uma alusão a uma cobra sul-americana considerada uma das maiores e mais perigosas do mundo.

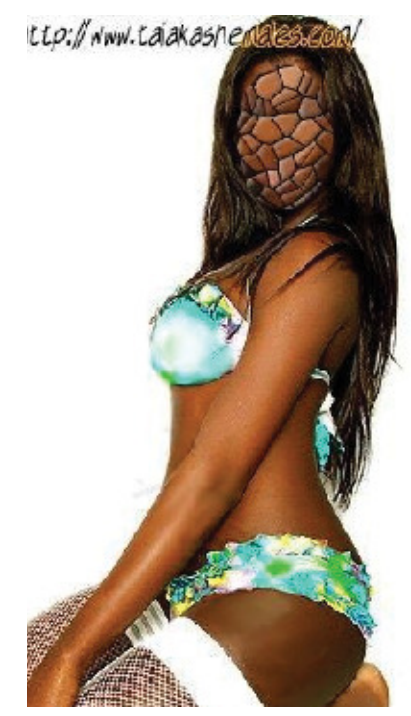

Figura 1 - Imagem de 'Anaconda Brasil' em anúncio de prestação de serviços sexuais, vestida com estampa da bandeira brasileira (http://www.taiakashemales.com/). 
Além da corporeidade de travestis brasileiras que exacerbam sua brasilidade nos anúncios sexuais, os sites de prestação de serviços também exploram símbolos da nação que, por sua vez, estão relacionados com a construção de uma nacionalidade racializada. Bhabha (2005) argumenta que a formação discursiva do sujeito colonial se dá na articulação das diferenças raciais e sexuais porque a raça e o sexo estão inscritas no corpo e simultaneamente e conflitivamente entram na economia do prazer e das relações de poder. A figura 2 é um interessante exemplo da articulação da construção discursiva da nacionalidade brasileira mesclada com a sexualidade e a racialidade.
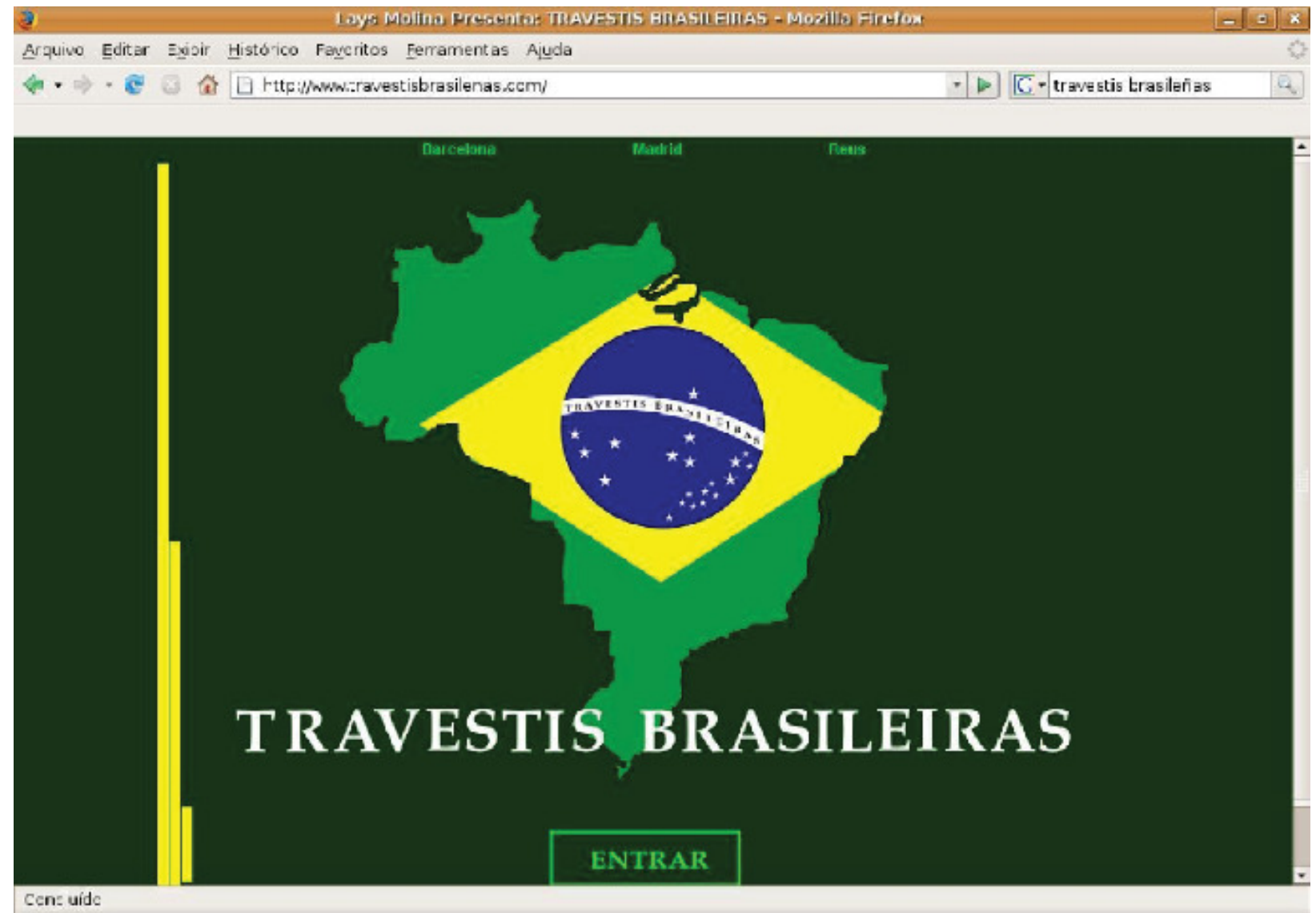

Figura 2 - Site de prestação de serviços sexuais de travestis brasileiras na Espanha (http://travestisbrasilenas.com/).

O site é apresentado ao som de 'Aquarela do Brasil' de composição de Ary Barroso em 1939, que acabou tornando-se a partir de 1942 uma das canções mais executadas que caracterizam o Brasil no exterior por ter sido tema do filme 'Saludos Amigos' dos Estúdios Disney e o surgimento do personagem estereotipado do povo brasileiro, o Zé Carioca. O personagem de Walt Disney que foi mostrado como personagem divertido, festeiro, vagabundo e preguiçoso. A alusão à faixa da bandeira brasileira que substitui o lema 'ordem e progresso' por 'travestis brasileiras'.

$\mathrm{O}$ encontro intercultural entre as travestis brasileiras e a sociedade espanhola possui algumas especificidades em relação a outros grupos de imigrantes. Elas não buscam enraizamento, não constituem família, descendentes, mantém o circuito de suas relações em torno de outros brasileiros, não buscam a formalização de documentação e de empregabilidade. Elas vivenciam a Espanha como um local de trânsito para preparar sua volta ao Brasil em um tempo mais curto possível que lhes possibilite reestruturar suas relações de poder.

As travestis brasileiras que realizam o trânsito internacional em direção à Espanha estabelecem práticas espaciais que na mediação entre si e os outros, conseguem jogar com desejos e fantasias, exacerbando elementos identitários que podem ser vantajosos nas relações do mercado sexual espanhol, promovendo um intenso movimento de interseccionalidade entre gênero, raça, sexualidade e classe. 


\section{A 'PISTA' E A 'PRAÇA': VIVÊNCIAS ESPACIAIS TRAVESTIS NA PRESTAÇÃO DE SERVIÇOS SEXUAIS}

Quando a travesti brasileira chega à Espanha, ela vivencia o país de forma restrita, pois o fato de ser imigrante ilegal, sua permanência no país e a realização do sonho de se constituir uma europeia, está constantemente ameaçado. Além disso, o exercício da atividade de prostituição, em geral, é realizado de forma clandestina e informal. Em geral, elas oscilam entre a prostituição na rua (a pista) e nos apartamentos ou clubes fechados (onde devem conseguir uma 'praça' ou vaga). As políticas de revitalização de algumas áreas de Madri, bem como o avanço da política anti-imigratória expressa nas constantes abordagens policiais tem levado à reorganização espacial da prostituição, com o aumento de atividades em espaços privados como os apartamentos e clubes.

$\mathrm{Na}$ visão das travestis, ambas as formas de organização da atividade apresentam vantagens e desvantagens. A modalidade de apartamento apresenta $58,9 \%$ de evocações negativas e $41,1 \%$ positivas. Entre as características negativas estavam relacionadas a vigilância constante por parte dos administradores, trabalho extenuante e impossibilidade de negar o cliente que a escolhe para a execução do serviço. As evocações positivas estiveram em torno da segurança e a comodidade, já que são os clientes quem procuram o apartamento com finalidade específica de contratar os serviços das travestis. As falas sobre as ruas são mais positivas do que negativas, $57,1 \%$ dos elementos discursivos expressam características positivas como a maior liberdade e autonomia na escolha do cliente e as negativas, com $42,9 \%$ em torno da insegurança, violência e exposição à polícia. Os trechos que se seguem são exemplares da tendência discursiva apresentada:

Olha, nas ruas você tem mais oportunidade de um cliente optar por você, porque ele para você, vem por você e te para. No piso, normalmente tem três ou quatro travestis. O cliente vem e o dono do piso apresenta todas e ele escolhe. E ele paga pro dono do piso, então é metade pra ti e metade pro dono do piso. Em piso, se cobra não menos que 70 euros por meia hora, é mais comum 100 euros por hora e daí é metade pra você e metade pra ele desse valor. E depois, você tem que estar 24 horas por dia disponível. Por exemplo, se você foi dormir às 3 da manhã e chega um cliente, você tem que levantar correndo de novo e se apresentar e você tem que estar maquiada, vestida, na pinta (risadas). Então, imagina, eu ia dormir maquiada e meia vestida. Se você levanta e está com o olho vermelho tem que dar aquela retocada e colocar a roupa rápido. Normalmente, como te disse durmo meia vestida, dentro do que cabe né. Daí tem que sair correndo e se apresentar. E daí tem que dar uma de hipócrita (risadas). Porque tu tá lá, morta de sono, já fodeu um montão e tem que aparecer descansada, com a pele linda e ainda 'toda cachonda, cachondíssima' que é excitada né, doida pra foder. A gente não tem assim um contrato, mas tem um acordo verbal assim, boca a boca. Se você liga, pede a vaga no piso, a pessoa que te recolhe já te diz: olha o esquema é 24 horas e tem só uma hora livre e se o cliente chegar, você se apresenta (Entrevista realizada com Talia, em Madrid, em 18/05/2008).

Todas as travestis entrevistadas já exerceram ou ainda exercem a atividade de prostituição organizada na rua ou em pisos por meio de conquista de uma vaga, conhecida como 'praça'. Esse sistema exige um deslocamento constante que constitui várias redes geográficas, cujos nós são as pessoas, donas dos pisos, em geral, cafetinas que podem ser brasileiras ou espanholas. Os deslocamentos ocorrem em torno de duas a três semanas entre os pisos, envolvendo cidades diferentes. As cidades mais citadas pelas pessoas entrevistadas possuem características de turismo ou são de médio a grande porte, como Madri e Barcelona, seguidas por Palma de Mallorca, Valencia, Bilbao, Zaragoza, Alicante e Murcia. Segundo elas, os deslocamentos constantes estão associados às necessidades e desejos dos clientes, conforme o depoimento que se seguem:

Olha, os clientes já acostumaram ter novidade na casa. Eles querem gente nova. Então, a gente tem que se deslocar. Se fica no mesmo local, não trabalha muito. Você trabalha bem no começo e depois começa abaixar. Daí é hora de sair. A gente entra em contato telefônico e arranja as praças (Entrevista realizada com Eurídice, em Madri, em 17/09/2008). 
Os deslocamentos entre as cidades são realizados por ônibus, menos vigiados pela polícia do que os aeroportos e o fato de estarem sempre em deslocamento, também dificulta serem apanhadas pelas autoridades de imigração. A vivência espacial das travestis brasileiras na Espanha, notadamente as que optam pela organização da atividade da prostituição em pisos vivencia apenas os nós das redes, que são os apartamentos onde ficam hospedadas e realizam os programas sexuais. O espaço da cidade como um todo não é conhecido ou desfrutado.

A atividade desenvolvida na rua envolve maior habilidade por parte da travesti, em todos os aspectos. Desde a conquista do local frente às outras travestis já estabelecidas na área, até a conquista do cliente, o drible da polícia e a autoproteção:

Você no mundo da prostituição, ou você é a filha da puta que bate em todo o mundo, tem que ser violenta, malvada, ou você faz como eu faço com todo o mundo, dô uma de simpática: 'Hola amiga, que tal?' Tem que ser simpática, chega, oferece um cigarro. Com amizade é mais fácil. Tanto onde eu já morei, onde eu moro hoje é assim que eu faço. Vou te dizer que em trabalho eu sempre fui uma boa pessoa, uma boa companheira. Por exemplo, na prostituição, você tem que fazer a linha 'intercâmbio de favores' né. Eu te ajudo no que eu posso e você no que pode pra mim. Por exemplo, se me convém ficar num lugar onde eventualmente eu não seria bem aceita, eu tento buscar maneiras para ser bem recebida. Por exemplo, na rua, a primeira vez que eu trabalhei na rua foi em Barcelona, já chegaram em mim e falaram: Quem é você? Quem te mandou trabalhar aqui? Fora daqui, se não te dou uma tunda! Eu digo bem mansinho: Hola, que tal? Tu éres tal tal tal, conheces tal persona. Pois é, é minha amiga e tal. Isso de pouco a pouco, tu te váz adentrando. Com simpatia, amabilidade, gratidão. Se alguém grita contigo: 'Fora daqui!' Você vai, mas no outro dia, você volta e vai tentando. No dia, quando está sendo mais aceita, já diz: 'Hola, guapa, como estás, te invito?' (mostrou um cigarro). Isso sem contar que todo pessoal, digo 80, 90 por cento do pessoal que trabalha na prostituição é dependente de drogas. Então se você chegar com um pouco de droga e dizer: 'Olha, toma pra ti, te invito à isso e tal', pronto. Quando te encontra, diz: 'Ah! Que simpática' e já virou assim tua amiga sabe. Se você 'regala' (presentear) uma carreira [cocaína], dessa aí que eu te ofereci, meu Deus, nossa, já é a melhor amiga (Entrevista realizada com Talia, em Madrid, em 18/05/2008).

Em ambas as espacialidades a droga é componente assíduo da atividade de prostituição para todas as travestis. A mais comum é a cocaína apesar de ter detectado a presença do crack. Nos pisos, os clientes, muitas vezes, não vão em busca de serviços sexuais, mas em busca de companhia e local protegido para o uso de substâncias químicas, como evidencia o relato que se segue:

Hoje em dia é maconha, coca e pastilhas de êxtase é que tá mandando nessa juventude viu. É a ordem do dia. A gente já viu muita coisa feia aqui viu. Porque os clientes, todos que vêm aqui, de hora em hora, eles querem cheirar. Se você não tem, ele vai embora. Eu vou ser sincera. Eu não tenho aqui, mas eu mando chamar. Eu não tenho porque, Deus me livre guarde, não quero me complicar. Mas eu chamo quem tem pra vender. E eles querem, procuram muito aqui pra isso, se drogar. Se não tem, eles não ficam. Eles perguntam: tem festa branca? (Entrevista realizada com Divina, em Madri, em 02/06/2008).

A espacialidade protegida dos pisos para o uso de drogas, se por um lado, traz proteção e segurança para as travestis, por outro, torna-as menos visíveis na sociedade espanhola e todas as conquistas sociais já realizadas pelo movimento LGBT na Espanha não atinge as travestis brasileiras que estão em situação de ilegalidade naquele país. As ruas, por meio da exposição dos corpos e de ações das travestis brasileiras, facilitam a visualização de sua presença pela sociedade espanhola que é ao mesmo tempo desejada e repulsiva. 


\section{NO 'TRUQUE': ENTRE AS REDES DE PESSOALIDADE E O TRÁFICO DE SERES HUMANOS}

A forma de organização das redes que possibilitam a entrada de travestis brasileiras na Europa e as características de relações de trocas de favores e cobranças realizadas não são reconhecidas, por elas, como sendo 'tráfico de seres humanos', em 75\% das evocações, mas 'truques' (enganar ou falsear alguma coisa com objetivo de tirar vantagem). Do total, 12,5\% das evocações estiveram ligadas a crença da existência de práticas de tráfico de seres humanos, lembrando experiências de pessoas e casos que foram vistos em programas de televisão. Outras evocações, $12,5 \%$, estiveram ligadas ao caso de Iris, que afirma ter sido traficada do Brasil para a Espanha. As falas das travestis brasileiras refletem a existência de um código moral próprio, não compreendido por elas como tráfico de seres humanos, conforme entende a sociedade espanhola. $\mathrm{O}$ trecho abaixo revela alguns dos elementos a serem considerados:

Sabe, a polícia muitas vezes não entende o mundo da gente sabe. Eles acham que é crime o que a gente faz. Eles não entendem. Dizem que uma pessoa que tem uma casa e, por exemplo, recolhe uma travesti, investe nela e depois quer o dinheiro que investiu de volta é cafetinagem. Mas veja, vem uma travesti, quer colocar peito, quer uma peruca e você ajuda ela se montar e ensina a vida a ela. Como que faz o serviço, como se defender, como ser uma travesti. Você faz a travesti e depois, é claro, quer o que investiu de volta. Imagina, uma pessoa que geralmente nem a mãe quer, a família rejeita e só tem a gente. Mas a polícia não entende a gente, como é que é a vida da gente e acha que isso é crime. Mas não é, é a forma como a gente vive, como podemos viver (Entrevista realizada com Ágape, em Madri, em 14/05/2008).

As redes que se instituem para o agenciamento de travestis brasileiras contêm elementos que envolvem afetividade, confiança e significados religiosos. Isso acaba dificultando a compreensão dos policiais de suas formas de organização. Os relatos que seguem são paradigmáticos nesse sentido:

A pessoa que me deu o dinheiro é uma pessoa muito boa, uma pessoa muito amiga e até hoje é uma grande amiga minha. Uma pessoa que não te explora, não te incomoda, não te dá nenhum tipo de problema. Inclusive, eu agradeço muito a ela. Foi ela que me ajudou, foi ela que me deu a luz. Queira ou não ela me deu a luz. Cobrando ou não cobrando, ela me deu a luz (Entrevista realizada com Pandora, em Madrid, em 16/09/2008).

Olha, eu sonhava em vir, mas aconteceu sabe. Foi de uma hora para outra que aconteceu. Eu sonhava e tinha conseguido uma casa no Brasil e daí surgiu uma oportunidade. Uma mulher brasileira me convidou. Me telefonou e perguntou se eu não queria vir para a Europa e eu falei, quero, mas não dei muito caso sabe. Daí, a sobrinha dela já apareceu com a passagem com tudo e pensei assim, bem se Deus tá abrindo as portas pra mim, eu vou né (Entrevista realizada com Ágape, em Madri, em 14/05/2008).

Essas redes informais, contudo, possuem grande eficiência de organização e de ações, pois são controladas pelos seus membros, a partir de um código moral estabelecido e pactuado. Se alguém quebrar com o acordo estabelecido deve receber punição exemplar, como pode ser exemplificado pelo trecho da fala de uma das participantes:

Então, eu vim financiada por sete mil euros. Eu trabalhava e mandava o dinheiro. Se você não paga, ela dá o jeito dela. Se você não paga ela manda te dar um doce. Manda te pegar, você entendeu? Então tem o caso de uma amiga minha que foi a última filha dela que levou doce no ano passado. (...) Porque é assim, ela sempre tem que pegar uma, porque ela traz muitas, ela tem um rebanho. Pra mostrar pras outras, tanto para as que estão aqui e para aquelas que estão chegando. Ela sempre escolhe uma e faz algo para exemplo para todas. Isso fica, você entendeu? Então, se você não paga, sabe que não fica bem. Porque a pessoa está aqui e aqui não tem como se esconder, porque você trabalha e o circuito é o 
mesmo. Você tem que por anuncio pra trabalhar e você está em todas as páginas, você depende disso, de publicidade. Mas você tem que saber que no nosso meio é assim. Se você dá um grito aqui, toda a Espanha fica sabendo. Quer dizer, as travestis brasileiras que estão na Espanha sabem (Entrevista realizada com Tétis, em Madri, em 20/08/2008).

Pode-se afirmar que as redes de relações que sustentam o desenvolvimento da atividade de prostituição de travestis brasileiras se estabelecem por múltiplas espacialidades que podem ser contraditórias e complementares entre si. A mesma rede que possibilita o intercâmbio de informações de praças em pisos são as que permitem também, a regulação de suas ações em um movimento paradoxal que posiciona as pessoas nas redes de poder.

\section{CONSIDERAÇÕES FINAIS}

O texto teve como fio condutor evidenciar o movimento da interseccionalidade entre raça, classe, gênero e sexualidade acionado por travestis brasileiras no processo de sua mobilidade transnacional para a Espanha. A experiência de travestis brasileiras que rompem as fronteiras nacionais e acessam outros países pode ser visível apenas por uma imaginação geográfica que permita evidenciar suas práticas complexas e fluídas, pois elas, apesar de toda forma de poder e violência a que estão submetidas, resistem, lutam e subvertem a pretensa ordem universal que teima em invisibilizar sua existência e conseguem tornar suas vidas possíveis, apesar do poder que oprime.

As travestis brasileiras avaliam os elementos de vantagens e desvantagens do país de origem e de recepção e procuram tirar proveitos das diferenças, mobilizando elementos identitários que provocam paradoxalmente desejo e repulsa. Ora mostram-se como brasileiras e usufruem de toda a significação racializada em torno dessa nacionalidade que desperta o desejo e a fantasia dos povos colonizadores. Essas táticas, ao mesmo tempo, se transfiguram em vantagens econômicas que, para pessoas com pouco rendimento e escolaridade, lhes garante ascensão financeira e também conquista de respeito junto a uma família pobre no Brasil. O desenvolvimento dessa trajetória espacial evidencia sua resistência à exclusão e ao preconceito que as colocam em situação de invisibilidade socioespacial. Mas é a própria invisibilidade que facilita seus fluxos e o desenvolvimento de estratégias para ultrapassar as fronteiras nacionais. Sua vivência na Espanha é marginal, pulverizada e dinâmica, organizada em redes informais que dificultam seu enraizamento e a captação da cultura do país receptor.

Elas resistem às normas estabelecidas, já que sua usual vivência marginal na sociedade brasileira naturaliza os elementos de ilegalidade que acabam fazendo parte de sua existência. A organização de suas redes de atividades de prostituição envolvem vários elementos de afetividade e religiosidade que dificultam a compreensão de suas práticas como sendo 'tráfico de seres humanos', mesmo que a sociedade espanhola assim a classifique.

\section{AGRADECIMENTOS}

Projeto financiado pela CAPES em 2008 para a realização de estágio pós-doutoral na Universidade Complutense de Madrid.

Esta reflexão jamais seria possível sem a generosidade de algumas pessoas que constituíram os nós das redes sociais que se pôde acessar no desenvolvimento da pesquisa em Madrid, com recursos provenientes da CAPES. Nossos sinceros agradecimentos à Isidro Garcia Nieto e Lola do Programa de informação aos homossexuais e transexuais da Comunidade de Madri, a Joeli da COGAM (Colectivo de Lesbianas, Gays, Transexuales y Bisexuales de Madrid ) e à July, bombadeira (termo que designa a pessoa que injeta o silicone líquido no corpo das travestis para construir as formas femininas) brasileira, falecida no início de 2011, em Curitiba - Paraná. 


\section{REFERÊNCIA BIBLIOGRÁFICA}

ARAUJO, Sandra Gil. Migraciones latinoamericanas hacia el Estado español. La reactivación del sistema migratorio transatlántico. In: RODRIGUEZ, Ileanna e MARTÍNEZ, Josebe. Postcolonialidades históricas: (in)visibilidades hispanoamericanas / clonialismos ibéricos. Barcelona: anthropos, 2008.

ASSOCIACIÓN MÉDICOS DEL MUNDO- ESPAÑA. Situación de la exclusión social em España. Madrid: Médicos del mundo, 2009.

BARDIN, Laurence. Análise de Conteúdo. Lisboa: Edições 70, 1977.

BHABHA, Homi K. O Local da Cultura. Belo Horizonte: Ed. UFMG, 2005.

BUTLER, Judith. Gender trouble: feminism and the subversion of identity. London: Routledge, 1990.

BUTLER, Judith. Bodies that matter: on the discursive limits of 'sex'. London: Routledge, 1993.

COLARES, Marcos. I Diagnóstico Sobre o Tráfico de Seres Humanos: São Paulo, Rio de Janeiro, Goiás e Ceará. Brasília: Ministério da Justiça, de Justiça, 2004.

CORRÊA, Mariza. A invenção da mulata. Cadernos Pagu, v. 6, n. 7, p. 35-50, 1996.

COSTA, Jean Carlo de Carvalho. Nação, estado e raça em Manoel Bomfim: ‘impertinência' bomfiniana em torno da identidade nacional. Cronos, v. 9, n.2, p. 417-438, 2008.

MASSEY, Doreen. Pelo espaço: uma nova política da espacialidade. Rio de Janeiro: Bertrand Brasil, 2008. MASSEY, Doreen; ALLEN, John; SARRE, Phillip. Human Geography Today. Cambridge: Polity Press, 1999. MCDOWELL, Linda. Gender, Identity and Place. Understanding Feminist Geographies. Minneapolis: University of Minnesota Press, 1999.

ORNAT, Marcio Jose. Espacialidades travestis e a instituição dos territórios paradoxais. In: SILVA, Joseli Maria. Geografias Subversivas: discursos sobre espaço, gênero e sexualidades. Ponta Grossa: Todapalavra, 2009, p. 177-210.

PATRICIO, Maria Cecília. No truque: fluxos migratórios de travestis brasileiras à Espanha. Uma perspectiva Transnacional. Disponível em: http://www.ram2009.unsam.edu.ar/paginas/GT.html.\%20Acesso\%20 em\%2020/02/2011.

PELÚCIO, Larissa. Exótica, erótica e travesti: nacionalidade e corporalidade no jogo das identidades no mercado transnacional do sexo. In: CASTRO, Ana Lúcia de. Cultura contemporânea, identidades e sociabilidades. Olhares sobre corpo, mídia e novas tecnologias. São Paulo: Cultura Acadêmica, 2010. p. 197-213. ROSE, Gillian. Feminist \& Geography: the limits of geographical knowledge. Oxford: Blackwell Publishers, 1993.

ROSE, Gillian. Performing Space. In: MASSEY, Doreen; ALLEN, John; SARRE, Phillip. Human Geography Today. Cambridge: Polity Press, 1999, p. $247-259$.

SASSEN, Saskia. Contrageografías de la globalización. Género $\mathbf{Y}$ ciudadanía em los circuitos transfonterizos. Madrid: Traficantes de sueños, 2003.

SCHWARCZ, Lilia K. Moritz. Espetáculo da miscigenação. Estudos Avançados, v. 8, n. 20, 1994.

SILVA, Joseli Maria Silva. A cidade dos corpos transgressores da heteronormatividade. In: SILVA, Joseli Maria. Geografias Subversivas: discursos sobre espaço, gênero e sexualidades. Ponta Grossa: Todapalavra, 2009, p. 135-150.

VALENTINE, Gill. Theorizing and Researching Intersectionality: A Challenge for Feminist Geography. The Professional Geographer, v 59, n. 1, p. $10-21,2007$.

VICENTE, Torrado T. La imigración latinoamericana em España. In: Expert Group Meeting on International Migration and development in Latin American and the Caribbean, 2005, Mexico. Anais... México: Disponível em http://www.un.org/esa/population/meetings/IttMigLAC/IttmigLAC_Mexico.htm, 2005, p. 1-29, Acesso em 12/01/2009.

Trabalho enviado em janeiro de 2013

Trabalho aceito em fevereiro de 2013 